\title{
Research
}

\section{Helpful strategies for GPs seeing patients with medically unexplained physical symptoms:}

\author{
a focus group study
}

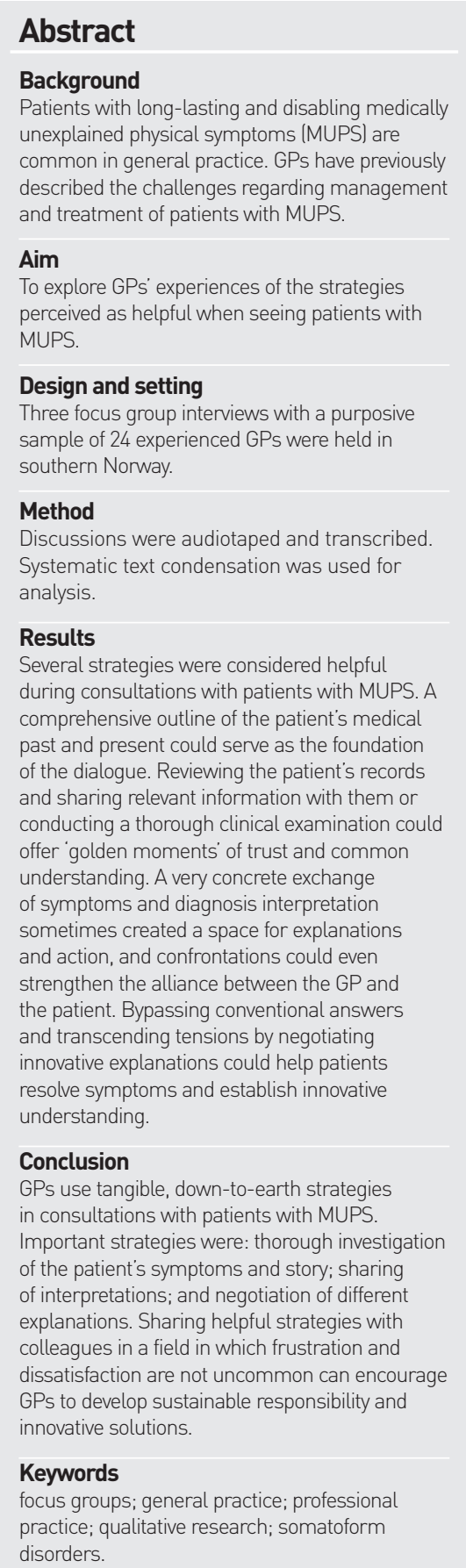

\section{INTRODUCTION}

Medically unexplained physical symptoms (MUPS) are conditions characterised by symptoms that do not have objective findings, such as chronic fatigue syndrome, fibromyalgia, and irritable bowel syndrome. ${ }^{1,2}$ Among researchers, there is no consensus on MUPS terminology, ${ }^{3}$ but patients with long-lasting and disabling MUPS are among the most common groups of patients seen in general practice. ${ }^{4,5}$ GPs have a major role to play in managing such patients, but encounters with them may lead to frustration for the practitioners and dissatisfaction for patients. ${ }^{6.7}$ Patients with MUPS are often referred to unnecessary investigations in secondary health care, which are costly and could have potential iatrogenic harms. ${ }^{8}$

Although research describes a lack of evidence on the effectiveness of various interventions, ${ }^{9}$ educational programmes and guidelines for GPs have been presented..$^{10-12}$ Nevertheless, medical students and doctors desire further knowledge about how best to manage and treat patients with MUPS. ${ }^{13,14}$ The authorship consists of four experienced GPs and a health researcher who share a special interest in MUPS. The authors were aware that GPs have not only frustrations within this field but also successful experiences that should be shared. Schön's theory of the reflective practitioner ${ }^{15}$ explains how such experiences may constitute hitherto unarticulated tacit knowing ${ }^{16}$ developed through 'reflection in action'. By talking systematically about such phenomena, the language used may provide access to the strategies applied by the practitioner, which may then be articulated as 'reflection on action' and shared. This study aimed to explore GPs' reflections on action, describing strategies they had experienced as helpful when treating patients with MUPS.

\section{METHOD}

A focus group design was chosen to take advantage of the communicative interaction between participants sharing their relevant experiences. ${ }^{17}$

\section{Recruitment and sample}

To obtain sufficient variation of descriptions, experienced participants were required. As such, GPs from three continuing medical education (CME) groups were invited to participate. Such groups are compulsory for GPs' continuing education in Norway. Participants were not offered incentives aside from CME credit points.

Data were drawn from three focus groups with a total of 24 participants. The purposive sample of GPs, who knew each other, included 17 men and seven women aged 33-68 years; all barring five were GP specialists. Participants had worked as GPs for a median of 24.5 years.
A Aamland, PhD, MD; A Fosse, MD, Research Unit for General Practice, Bergen, Norway. E Ree $\mathrm{PhD}$, University of Research Health, Bergen, Norway. E Abildsnes, PhD, MD, Department of Global Public Health and Primary Care, University of Bergen, Norway. K Malterud, PhD, MD, Research Unit for General Practice, Uni Research Health, Bergen, Norway; Department of Global Public Health and Primary Care, University of Bergen, Norway.

Address for correspondence Aase Aamland, Research Unit for General
Practice, Uni Research Health, Kalfarveien 31, N-5018 Bergen, Norway.

E-mail: aase.aamlandagmail.com Submitted: 30 November 2016; Editor's response: 31 January 2017; final acceptance: 23 February 2017.

\section{@British Journal of General Practice}

This is the full-length article (published online 4 Jul 2017) of an abridged version published in print. Cite this version as: Br J Gen Pract 2017; DOI: https://doi.org/10.3399/bjgp17X691697 


\section{How this fits in}

GPs have previously described the challenges regarding the management of patients with medically unexplained physical symptoms (MUPS). In this study, experienced GPs shared strategies they had perceived as helpful when treating patients with MUPS, such as a thorough review of symptoms and story, negotiation of investigation plans, and mutual development of innovative and constructive explanations. Such knowledge may encourage GPs to develop sustainable responsibility and innovative solutions, enabling them to better manage and treat patients with MUPS.

\section{Data collection}

The focus group interviews, lasting about 90 minutes took place in scheduled meetings for the CME groups. Prior to the meeting, participants were encouraged to recall memories about events that included any strategies used that they perceived as helpful. During discussions, participants commented, reflected, and shared similar experiences.

The critical incident technique ${ }^{18,19}$ was chosen to enhance reflection on action. ${ }^{15}$ This is a procedure for 'collecting' incidents that can contribute to solving practical problems. Participants were asked to recall encounters with patients with MUPS who had made a positive change. When stories appeared to refer to patients who had health problems other than MUPS, such as mental disorders, material was excluded from the analysis.

An observer took notes, summarised their impressions at the end of the interview, and sought clarity to correct potential misunderstandings.

Interviews were audiotaped, transcribed verbatim, and encrypted. Assessment of information power guided the sample size by considering the following dimensions of the study design: aim of the study, sample specificity considering aim, use of established theory, quality of dialogue, and the chosen analysis strategy. ${ }^{20}$

The interviews included intensive dialogue, and a thematic cross-case analysis was applied to the interviews. In this case, the adequate supply of the requested experiences within the sample, the theoretical support of analysis, and the intensive dialogue were emphasised, although the cross-case analysis required a larger sample compared, for example, with a narrative analysis. After three interviews, the authors judged the information power to be sufficient to perform analyses.

\section{Analysis}

Systematic text condensation (STC), a method for thematic cross-case analysis, was used. ${ }^{21}$ The method comprises four stages:

- read all the material to obtain an overall impression and recognise preliminary themes;

- develop code groups from preliminary themes by identifying meaning units reflecting different aspects of the strategies perceived as helpful by the participants, and coding for these;

- establish subgroups that exemplify the vital aspects of each code group, then condense the contents of each and identify illustrative quotations for each; and

- synthesise the condensates from each code group, presenting a reconceptual description of each category regarding strategies experienced and considered helpful by participants.

Analysis was supported by Schön's theory about the reflective practitioner to sharpen the researchers' focus towards verbalisation of previously unarticulated practice conduct. ${ }^{15,22}$ Analysis was carried out by three of the authors.

\section{RESULTS}

Analysis demonstrated a broad range of strategies experienced as helpful in consultations with patients with MUPS:

- a comprehensive outline of the medical history up to the present time - this could act as the foundation of the dialogue between GP and patient; reviewing the patient's record, sharing relevant information with them, or conducting a thorough clinical examination - these actions could lead to 'golden moments' of trust between doctor and patient, and help both to reach a common understanding;

- very concrete exchange of symptom and diagnosis interpretation - on occasion, this was noted to allow for a space for explanations and action; confrontation - this could sometimes strengthen the alliance between the GP and the patient; and

- bypassing conventional answers and transcending tensions by negotiating innovative explanations - this could help patients resolve symptoms and establish innovative understanding. 
These findings will be elaborated on further below.

The identifying names used after the quotes are pseudonyms that denote only the gender of the participant.

\section{A comprehensive outline of the medical past and present as the foundation of the dialogue}

Many of the participants reported that being well prepared for the clinical mission was a useful starting point. Some shared their experiences of systematically reviewing the patient's record from start to end, thereby organising useful information and preparing for a breakthrough in a challenging counselling process.

Due to time limits, such efforts were usually undertaken outside scheduled appointments. One participant described how he summarised all examinations and treatments conducted over the years, and showed the list to the patient. Such a procedure could reveal how the endeavours had been going in circles, leading to unnecessary actions and dead ends, but also to useful clarifications. Such a list became an important consultation tool, preventing new, unwarranted examinations. Furthermore, these summaries were intended to show the patient that they knew the story in detail. According to many participants, 'going through the paperwork had been constructive in their work with longstanding patients, as well as new ones.

Another helpful and less time-consuming strategy presented by several participants was reading the last consultation notes, recalling results from previous tests, and quickly recapitulating the patient's history before calling in the patient. Through such preparation, participants wanted to demonstrate to patients that their concerns had been recognised, so the consultation could start where the former had been closed.

Some participants would 'lean back' and allow the patient 'get it all off their chest' without interrupting during the first minutes of the consultation; others would express empathy by telling the patients they remembered their struggles and symptoms, so the patient hopefully would not feel as though they needed to convince the GP

One participant described how he prepared the consultations with a patient with many different health problems whom he had known for 20 years:

I try to be very systematic when I write the summary in order to remember what
I have done. I feel this as a strength when I can tell the patient that we have done this and that. It's like you said about [nodding to another participant] "going through the paperwork"... / sometimes browse through the summary to memorise what we actually have done. And when she talks about this pain just here [pointing at the throat] or in the stomach and so on ... then I can tell her when we last examined those symptoms, and then she says, "Oh yeah, I trust you!" This makes me feel that we have been through something together that enables me to soothe her with her own story.' (Joe)

Several participants emphasised their habit of doing a thorough clinical examination of their patients, even when they were certain they would not find anything pathological. One participant said that, if a patient had back pain, she routinely examined their back, including laying the patient on the bench so she could test their reflexes. She felt patients expected this to happen when seeing a doctor.

The participants also used the clinical examination to demonstrate and explain the relationship between body and mind for their patients. One participant spoke of a patient sitting with elevated shoulders when she measured his blood pressure; she then focused on the patient's breath and explained the importance of breathing with the diaphragm. It was a golden moment', she said, when the patient then saw that his blood pressure dropped and he realised he could affect this by correcting his posture.

One of the participants described how his procedures had changed during his career:

I must say that I have begun to examine more in recent years. Like, I do more regular examinations; touch the belly, listen, and examine. I do not expect to find anything, but then I come a bit further in getting good contact with the patient.' (Paul)

\section{Very concrete exchange of symptom and diagnosis interpretation}

One participant described a patient who wrote him a long letter in which she described all her symptoms. Reviewing this description together, they elaborated an examination plan, agreeing to terminate the examinations when the plan was complete, even if the tests did not reveal any findings. The participants often warned their patients that $X$-rays and MRI scans would not always reveal any causal understanding, and were possibly just indications of 'wear and tear'. After doing so, patients would often refrain 
from further requests for referrals and examinations, they said.

Some participants described how they managed to convince the patient that they believed in their symptom experience, even in situations where both the GP and patient had divergent causal understandings. One participant spoke of a patient whose causal explanations he did not accept. Still, he did not confront the patient with his disapproval, but he rather 'played the game', intending to create space for action in the therapeutic relationship.

On the other hand, confrontations could sometimes be necessary as well as constructive. One participant described a painful experience with a patient who demanded strong painkillers that she would not prescribe. The two of them ended up in a rather intense quarrel, but managed in time to work through the crisis. Afterwards, the participant felt that a more positive relationship with her patient had developed.

Many participants articulated how they felt that a long relationship with patients, including positive as well as negative experiences, could strengthen the alliance. One participant described his approach with a patient who was convinced that his symptoms were caused by electromagnetic hypersensitivity:

My strategy was then to tell him that we didn't have any medical documentation that his symptoms were caused by harmful electromagnetic radiation, but that I accepted and believed that he experienced the symptoms ... If I had rejected him and told him that his symptoms didn't fit with any medical condition, that I didn't believe him, then I guess he would have found a new GP, and then another and another until somebody would accept his symptoms ... In this way, we have kept the alliance and I have been able to help him through many difficult situations.' (Oliver)

Several participants emphasised the importance of constructive dialogue and cooperation with other health professionals. This was partly for better evaluation of the patients, but also to increase their patients' confidence in their expertise and the decisions they made. For example, one participant collaborated with a health visitor and a mental health nurse, helping a teenage girl with chronic pain. Together, she said, they focused on appearing as a team to support the girl and her parents, agreeing on causes and further strategy. Talking positively about other health professionals in front of their patients was also mentioned as a strategy to increase the patients' confidence in the healthcare system. When one of the participants received a clinical report from a physiotherapist, he told the patient about his positive experiences with this physiotherapist regarding other patients as well.

The participants explained how giving a diagnosis could be helpful for their patients. Several argued how a diagnosis could change the patient's focus from searching for a diagnosis to finding a way to live with their complaints. One participant spoke of a patient who described how she used the irritable bowel syndrome diagnosis to explain her distressing symptoms to those around her. This doctor had changed her perception of MUPS diagnoses during her career and said:

Well, I have experienced, from my work with a lot of patients with MUPS, that a diagnosis actually has been of crucial importance ... the fact that I have actually dared to diagnose... Earlier, I was much more afraid of calling it, for instance, fibromyalgia. (Jessica)

\section{Bypassing conventional answers and transcending tensions by negotiating original explanations}

Several participants talked about their experiences of daring to ask simple, direct, and open questions, trying to make the dialogue concrete and personalised. A participant described his strategy for reframing the many symptoms that were sometimes explained in a rather chaotic way during consultations - he would write down, word for word, what the patients said about their complaints, and then read it back to them. This strategy seemed to help the patients to differentiate and prioritise the most disabling symptoms.

Some of the most experienced participants reflected on the value of just being present for their patients, instead of constantly proposing new investigations or treatments. They described how they sometimes refused, in a constructive way, patients' requests for new investigations as they had previously experienced how endless investigations could, in fact, act as negative perpetuating factors. One participant reflected on the quality of dialogue:

In a way, I think the communicative dialogue between me and my patients with MUPS is far more important than what I actually do with them ... that my communicative style is my most important work tool, so to say.' (Dave) 
Some participants reflected on positive experiences with less evidencebased treatments, such as the Lightning Process ${ }^{23}$ for patients with chronic fatigue syndrome or the FODMAP Ifermentable oligosaccharides, disaccharides, monosaccharides, and polyols) diet for patients with irritable bowel syndrome. They said they had felt quite uncomfortable when underpinning or recommending such therapies due to lack of evidence of their effectiveness, but admitted they had seen dramatic changes in symptom load and function for a few patients.

Constructive explanations were often mentioned as useful to prevent rejections and bypass possible fights about the correct understanding of the illness. The participants emphasised, however, that the account should be based on medical evidence, although with pragmatic adaptations. One participant described a patient with long-lasting fatigue who came to see her, asking for blood tests to look for any deficiency conditions. As the participant had known the patient and other family members for several years, she knew quite a lot about the past and present pressures on her. The doctor had drawn a graph, which illustrated a basic principle that constant effort resulting in sustained activation may end in a collapse. Through dialogue, they found a common understanding of the symptoms, the cause of which was far from being a deficiency condition.

One participant described a specific narrative approach. After examinations had revealed only negative test results, he would reframe the patient's history:

'(I would say] "Now we are going to make up a history together, which we both have to believe in. It does not necessarily represent the truth but, if we both believe in it, we may come one step further" [Yet, the GP admitted] I may then make use of some more alternative explanations, maybe taking some medical shortcuts but, if it is not too far away from my medical knowledge, I would go for it ... If the patients have a narrative they believe in, instead of being rejected by "nothing is wrong with your tests"... I have seen how that has been really useful for several of my patients. (John)

\section{DISCUSSION}

\section{Summary}

A variety of consultation strategies were identified by the participants, including a comprehensive medical workout, a very concrete exchange of symptom and diagnosis interpretation, or negotiation of innovative explanations.

\section{Strengths and limitations}

The notion of 'patients with MUPS' seems to have high face validity among Norwegian GPs. Still, several participants expressed that they had been struggling to recollect experiences with helpful strategies as those cases that were frustrating and difficult more easily came to mind. Nevertheless, prior reflection seemed necessary for the discussion and is likely to have strengthened the internal validity of the study.

The participants had prepared for the interviews in different ways: some brought notes they had written, others brought printouts from electronic records, and a few recalled experiences from memory. The participants vividly recalled and shared different experiences in a positive atmosphere. No long periods of silence during the interviews were observed - this is likely to be because the participants knew each other in advance and were familiar with discussing case stories and talking about these matters in an environment comparable with regular CME meetings. Furthermore, the participants were experienced GPs, who were offered a safe atmosphere in which to articulate their tacit practices - something that was confirmed by the researchers observations of spontaneous comments, follow-up questions, and associations from other group members. The moderator sporadically intervened when participants were talking about the difficulties of managing patients with MUPS, as the aim of the study was to identify helpful strategies.

The participants gave the impression that they were neither particularly committed to, nor extraordinarily interested in, patients with MUPS as they had only accepted to participate in a regular meeting in their CME group about this study's theme, indicating the strength of external validity related to this study's sample. Around 30-40\% of consultations in Norwegian general practice last for more than 20 minutes. ${ }^{24}$ The transferability of this study's findings to contexts with consultations of much shorter duration may therefore be challenging.

The participating GPs reported strategies they had perceived as helpful. However, the choice of a focus group design also had some limitations. Patient perspectives would be needed if the study aim included assessment of the mutual interpretation and consequences of assumedly successful strategies. Furthermore, if the purpose 
was to study behaviour and interaction, an observation design should have been chosen. Both the moderator and the observer were GPs. Being a peer may open up opportunities for honest, direct communication but a research team with a different professional background might have encouraged the participants to present other kinds of experiences. Having a nonclinician on the team may have reduced GPs' 'blind spots' and could have hampered the reflection on action following reflection in action as indicated by Schön. ${ }^{15}$

\section{Comparison with existing literature}

This is not the first study to present strategies intended to enhance a therapeutic alliance between doctors and patients with MUPS. Previous research has, for instance, recommended: explicitly confirming trust in patients' symptoms, despite a lack of objective signs; striving for an open and direct communication style; and 'performing' thorough clinical examinations and making a plan for further examinations in cooperation with the patients. $9.11,12,25-28$ The analysis presented here adds to this body of existing knowledge by presenting very concrete and feasible strategies that experienced GPs perceived as helpful in their consultations with patients with MUPS.

Taking Schön's ${ }^{15}$ perspectives to articulate reflection in action, it has been possible to approach practical management and specify some tangible and specific strategies. These strategies represent knowledge that has been gained through individual clinical experience, not that which is extensively presented in textbooks or guidelines. Analysis indicates that this is a perspective that offers considerable potential to develop innovative, experience-based knowledge from other domains within general practice where challenges are abundant and skills are limited, such as with mental health problems or musculoskeletal complaints. GPs seem to continuously adjust their actions to the context in which individualised approaches are needed while, at the same time, cultivating personalised proficiencies that deserve to be shared.

A recent review about the challenge of diagnosing different MUPS disorders in primary care describes numerous barriers to the application of such diagnoses..$^{29}$ A diagnosis can benefit the patient by providing an explanation and demonstrating that the doctor has knowledge about the condition; however, it may harm the patient by mediating cultural stereotypes or therapeutic pessimism - everything depends on the doctor's attitude. Some participants in the study presented here reflected upon how, through experience, they had shifted from scepticism to acceptation regarding diagnoses such as fibromyalgia and chronic fatigue syndrome, as a means to terminate further unnecessary examinations and to offer a useful starting point for rational explanations, reconciliation, and coping. In line with this, Burton et al suggested that GPs explain symptoms to patients in a rational way that is acceptable and makes sense to both parties ${ }^{30}$ - this is what others have called 'empowering explanations. ${ }^{31}$ This may help the patients to make sense of their symptom experiences and foster therapeutic action. ${ }^{30}$

A recent study examined 138 audiotaped explanations given to patients with MUPS and identified three components: facts, mechanisms, and causes. ${ }^{32}$ The analysis presented here substantiates how GPs may feel insecure about offering such explanations due to lack of biomedical knowledge and the need for pragmatic adaptations of popular explanations. However, in contrast with a study by Stone, ${ }^{26}$ the findings presented here clearly substantiate how experienced GPs may be able to incorporate physical as well as psychological aspects into their explanations.

Offering enhanced team-based care to patients with MUPS has previously been recommended, ${ }^{11,25,33}$ but whether this can really be provided depends on how the healthcare system is organised. Norwegian primary health care is not well organised for regular team-based care, which could be why the participants in this study placed little emphasis on this. Nevertheless, they did express how recognising other professionals' judgements, striving for common language, and developing management plans could be helpful strategies. These findings may serve as an argument for facilitating cooperation between different professionals to counteract inexpedient fragmentation in primary health care as outlined by the Norwegian government. ${ }^{34}$

Less experienced GPs call for more knowledge about managing patients with MUPS $^{14}$ and strategies cited as helpful in this study could be used in teaching. Nevertheless, learning from personal encounters with patients with MUPS is of utmost importance, as experience is mandatory for establishing reflection in action and further learning by reflection on action. CME groups discussing case 
stories and communication strategies may be a suitable arena for reflection on action and the elaboration of successful experiences. ${ }^{35,36}$

\section{Implications for practice}

Through reflection on action, GPs identified tangible, down-to-earth strategies used in their consultations with patients with MUPS. These included time-consuming preparation as well as spontaneous actions. Important strategies included a thorough review of the patient's story, along with mutual interpretation and negotiations of symptoms, which were intended to show the patient that the GP knew their story in detail. These strategies deserve further elaboration to become skills with a capacity for adaptation to individual competences and subsequent transferral to more inexperienced GPs in need of tools.

Sharing helpful experiences with colleagues in a field where frustration and dissatisfaction are not uncommon can encourage GPs to develop sustainable responsibility and innovative solutions. Such individualised strategies could serve as a basis for the development of practical tools for GPs to help them manage patients with MUPS.

Communicating experience-based knowledge in very practical terms - thereby emphasising the strengths and potentials of lessons learned in action - is a promising approach for understanding and managing complicated medical challenges.

\section{Funding}

Economic support for this project was provided by Eckbos Legat, Norway.

\section{Ethical approval}

The participants presented their experiences without revealing identifiable information of patients. The Regional Committee for Ethics in Medical Research assessed the study to be outside their mandate (2015/1147). The Norwegian Social Science Data Services (now known as the Norwegian Centre for Research Datal approved the study (43862/3/MHM). The work was carried out in accordance with the World Medical Association Declaration of Helsinki (Declaration of Helsinki). All patient identifiers have been removed or disguised so patients described cannot be identified through the details of the story.

\section{Provenance}

Freely submitted; externally peer reviewed.

\section{Competing interests}

The authors have declared no competing interests.

\section{Acknowledgements}

The authors would like to thank the GPs who participated in the focus groups.

\section{Discuss this article}

Contribute and read comments about this article: bjgp.org/letters 


\section{REFERENCES}

1. Mayou R. Medically unexplained physical symptoms. BMJ 1991; 303(6802): 534-535.

2. Burton $\mathrm{C}$. Beyond somatisation: a review of the understanding and treatment of medically unexplained physical symptoms (MUPS). Br J Gen Pract 2003; 53(488): 231-239.

3. Creed F, Guthrie E, Fink $P$, et al. Is there a better term than 'medically unexplained symptoms'? J Psychosom Res 2010; 68(1): 5-8.

4. de Waal MW, Arnold IA, Eekhof JA, van Hemert AM. Somatoform disorders in general practice: prevalence, functional impairment and comorbidity with anxiety and depressive disorders. Br J Psychiatry 2004; 184(6): 470-476.

5. Aamland A, Malterud K, Werner EL. Patients with persistent medically unexplained physical symptoms: a descriptive study from Norwegian general practice. BMC Fam Pract 2014; 15(1): 107.

6. Hartz AJ, Noyes R, Bentler SE, et al. Unexplained symptoms in primary care: perspectives of doctors and patients. Gen Hosp Psychiatry 2000; 22(3): 144-152.

7. Werner A, Malterud K. It is hard work behaving as a credible patient: encounters between women with chronic pain and their doctors. Soc Sci Med 2003; 57(8): 1409-1419.

8. Nimnuan C, Hotopf M, Wessely S. Medically unexplained symptoms: an epidemiological study in seven specialities. J Psychosom Res 2001; 51(1): 361-367.

9. den Boeft M, Claassen-van Dessel N, van der Wouden JC. How should we manage adults with persistent unexplained physical symptoms? BMJ 2017; 356: $\mathrm{j} 268$.

10. Fink P, Rosendal M, Toft T. Assessment and treatment of functional disorders in general practice: the extended reattribution and management model - an advanced educational program for nonpsychiatric doctors. Psychosomatics 2002; 43(2): 93-131.

11. olde Hartman TC, Blankenstein AH, Molenaar AO, et al. NHG-Standaard Somatisch Onvoldoende verklaarde Lichamelijke Klachten (SOLK) [NHG guideline on medically unexplained symptoms (MUS)]. Huisarts Wet 2013; 56(5): 222-230.

12. Chitnis A, Dowrick C, Byng R, et al. Guidance for health professionals on medically unexplained symptoms (MUS). http://www.rcpsych.ac.uk/pdf/ CHECKED MUS Guidance_A4_4pp_6.pdf (accessed 9 Jun 2017).

13. Howman M, Walters K, Rosenthal J, et al. Teaching about medically unexplained symptoms at medical schools in the United Kingdom. Med Teach 2012; 34(4): 327-329.

14. Yon $\mathrm{K}$, Nettleton $\mathrm{S}$, Walters $\mathrm{K}$, et al. Junior doctors' experiences of managing patients with medically unexplained symptoms: a qualitative study. BMJ Open 2015; 5(12): e009593.

15. Schön DA. The reflective practitioner: how professionals think in action. New York: Basic Books, 1983.

16. Polanyi M. The tacit dimension. Gloucester, MA: Peter Smith Publisher, 1983.

17. Morgan D, ed. Focus groups as qualitative research. 2nd edn. Thousand Oaks, CA: Sage Publications, 1997
18. Flanagan JC. The critical incident technique. Psychol Bull 1954; 51(4): 327-358

19. Bradley CP. Turning anecdotes into data - the critical incident technique. Fam Pract 1992; 9(1): 98-103.

20. Malterud K, Siersma VD, Guassora AD. Sample size in qualitative interview studies: guided by information power. Qual Health Res 2015; 26(13): 1753-1760.

21. Malterud K. Systematic text condensation: a strategy for qualitative analysis. Scand J Public Health 2012; 40(8): 795-805.

22. Malterud $\mathrm{K}$. Theory and interpretation in qualitative studies from general practice: why and how? Scand J Public Health 2016; 44(2): 120-129.

23. Crawley E, Mills N, Hollingworth W, et al. Comparing specialist medical care with specialist medical care plus the Lightning Process for chronic fatigue syndrome or myalgic encephalomyelitis (CFS/ME): study protocol for a randomised controlled trial (SMILE Trial). Trials 2013:14: 444.

24. Helfo. Maltall for refusjonsomradet lege. [Doctors' refunds]. https://helfo.no/ Documents/Analyser og rapporter/M\%C3\%A5ltall refusjonsomr\%C3\%A5de lege 2015.pdf (accessed 9 Jun 2017).

25. Heijmans $M$, olde Hartman TC, van Weel-Baumgarten E, et al. Experts' opinions on the management of medically unexplained symptoms in primary care. A qualitative analysis of narrative reviews and scientific editorials. Fam Pract 2011; 28(4): 444-455.

26. Stone L. Reframing chaos: a qualitative study of GPs managing patients with medically unexplained symptoms. Aust Fam Physician 2013; 42(7): 501-502.

27. Malterud K. Women's undefined disorders: a challenge for clinical communication. Fam Pract 1992; 9(3): 299-303.

28. Stensland P, Malterud K. Approaching the locked dialogues of the body. Communicating symptoms through illness diaries. Scand J Prim Health Care 1999; 17(2): 75-80.

29. Murray AM, Toussaint A, Althaus A, Löwe B. The challenge of diagnosing nonspecific, functional, and somatoform disorders: a systematic review of barriers to diagnosis in primary care. J Psychosom Res 2016; 80: 1-10.

30. Burton C, Lucassen P, Aamland A, olde Hartman T. Explaining symptoms after negative tests: towards a rational explanation. J R Soc Med 2015; 108(3): 84-88.

31. Salmon P, Peters S, Stanley I. Patients' perceptions of medical explanations for somatisation disorders: qualitative analysis. BMJ 1999; 318(7180): 372-376.

32. Morton L, Elliott A, Cleland J, et al. A taxonomy of explanations in a general practitioner clinic for patients with persistent 'medically unexplained' physical symptoms. Patient Educ Couns 2017; 100(2): 224-230.

33. Rosendal M, Blankenstein AH, Morriss R, et al. Enhanced care by generalists for functional somatic symptoms and disorders in primary care. Cochrane Database Syst Rev 2013; 10: CD008142.

34. Ministry of Health and Care Services in Norway. The primary health and care services of tomorrow - localised and integrated. Ministry of Health and Care Services in Norway, 2015.

35. Abildsnes E, Flottorp S, Stensland P. Case stories in general practice: a focus group study. BMJ Open 2012; 2(4): e001208.

36. Lid TG, Eraker R, Malterud K. 'I recognise myself in that situation ...' Using photographs to encourage reflection in general practitioners. BMJ 2004; 329(7480): 1488-1490. 